\title{
Quantitative correlation between transcriptional levels of ER chaperone, peroximal protein and FVIII productivity in human Hek-293 cell line
}

\author{
Evandra Strazza Rodrigues ${ }^{1,3,4^{*}}$, Virgínia Picanço-Castro ${ }^{1}$, Marta Regina Espanhol', \\ Luiz Alberto Martins de Andrade1, Patricia Vianna Bonini Palma', Simone Kashima ${ }^{1,3,4}$, \\ Aparecida Maria Fontes ${ }^{1,2}$ and Dimas Tadeu Covas ${ }^{1,2,4}$
}

\begin{abstract}
Hek-293 cell line presents good production platform for recombinant therapeutic proteins, however little is known about the components that contribute to the cellular control of recombinant protein production. In this study, we generated a Hek-293 producing recombinant factor VIII (FVIII) and we evaluated the immunoglobulin-binding protein (BiP) and phytanoil-CoA a-hydroxylase (PAHX) expression levels which are known for diminishing FVIII production. Our analyses showed that the recombinant cell population expresses $3.1 \pm 1.4$ fold of BIP mRNA $(P=0.0054)$ and $97.8 \pm 0.5$ fold of PAHX mRNA $(P=0.0016)$ compared to nontransduced cells. The amount of these proteins was inversely correlated to the secreted FVIII. In conclusion, BIP and PAHX expression are augmented in human cells producing FVIII and they antagonize the amount of therapeutic factor VIII in the cell culture.
\end{abstract}

Keywords: ER BIP chaperone; Factor VIII; Hemophilia A; PAHX gene expression and Recombinant Factor VIII $\triangle B$

\section{Introduction}

Hemophilia A is a hemorrhagic disease caused by insufficient levels or complete absence of functional coagulation factor VIII (FVIII) in the circulation. Hemophilic patients show spontaneous bleeding episodes primarily in soft tissues and joints. This clinical condition can also cause potentially life-threatening hemorrhages in muscles, internal organs and central nervous system (Ghosh 2004; Zago et al. 1987; Antunes et al. 2003).

The current treatment of hemophilic patients consists of prophylactic or therapeutic replacement of the deficient factor by intravenous infusions of FVIII plasma-derived concentrates or recombinant FVIII (rFVIII). Increasingly, the reposition therapy with FVIII concentrates from plasma is substituted by rFVIII produced by mammalian cells culture (Lee 1999; Neidhardt et al. 2005). This source of FVIII brought important therapeutic improvements due to the

\footnotetext{
* Correspondence: evandra@hemocentro.fmrp.usp.br

${ }^{1}$ Hemotherapy Center of Ribeirão Preto , Faculty of Medicine in Ribeirão Preto-FMRP, University of São Paulo-USP, São Paulo, Brazil

${ }^{3}$ Faculty of Pharmaceutical Sciences in Ribeirão Preto-FCFRP, University of São Paulo-USP, São Paulo, Brazil

Full list of author information is available at the end of the article
}

advantage over the safety of recombinant products compared to those that are plasma-derived. During the 80s, plasma derived products were connected to the spread of HIV and/or hepatitis viruses among thousands of hemophilic patients (Stanley 2006).

Recombinant coagulation factor products are already available in the market for 20 years. So far, FVIII recombinant proteins are produced in murine cells $\mathrm{CHO}$ or BHK (Baxter 2010; HealthCare 2009; Wyeth Pharma Pfizer 2007). Although these products have proved to be very similar to the FVIII derived from plasma, recombinant FVIII shows a pattern of nonhuman posttranslation modifications (PTM).

FVIII is one of the largest and most complex protein in the market and is produced by recombinant DNA technology (Jiang et al. 2002). This factor is submitted to multiple PTM, particularly glycosylation. Incorrect reproduction of these PTM in a nonhuman expression system may trigger immune reactions and lead to the formation of inhibitors against FVIII. Thus it will be essential to find human cell lines to produce recombinant FVIII with the same glycosylation pattern as the plasma protein. The advantages of using human cell-based 
expression systems is the high similarity of PTM and the absence of antigenic residues that commonly are present in rFVIII from licensed hamster cell-lines like as cited above (Durocher and Butler 2009). Some studies have associated human HEK 293 cell with a promising potential to rFVIII production in large-scale, using serum-free suspension technology (Picanço et al. 2007; Swiech et al. 2011).

The HEK 293 human embryonic kidney cell line is more often used by the scientific community for the production of recombinant proteins. This strain has rapid growth and it is highly susceptible to transfection and viral transduction (Durocher et al. 2002; Thomas and Smart 2005). Furthermore, there is a commercial adapted version of this strain suspension (Free Style 293-F Cells) which allows the production of large-scale recombinant proteins (Invitrogen Corporation 2007).

Although many PTM are required to obtain a active and non immunogenic FVIII, recombinant FVIII interacts with a number proteins, including calreticulin, calnexin, and immunoglobulin-binding protein (BIP), thus a significant proportion of the FVIII molecule is retained within ER, thereby limiting the transportation of FVIII to the Golgi apparatus. Previous studies showed that the over-expression of BIP inhibits FVIII secretion (Morris et al. 1997) and the antisense RNA expression for BIP reduces BIP levels and improves FVIII secretion (Brown et al. 2011). Another FVIII binding protein, correlated negatively with FVIII expression, is phytanoylCoA $\alpha$-hydroxylase (PAHX). This human protein is a peroxisomal enzyme that not only diminishes FVIII secretion into culture media, but also changes FVIII-A2 intracellular distribution (Chen et al. 2001). Interactions between FVIII and these proteins may limit FVIII productive secretion. Therefore, the strategy for overcoming such limitations may be known the alterations of endoplasmic reticulum (ER) chaperones and peroxisomal components that might contribute to the cellular control of recombinant protein production.

In this study, we evaluated the levels of BIP and PAHX in clones producing FVIII with a partially deleted Bdomain $(\mathrm{rFVIII} \Delta \mathrm{B})$. We found that even using a human cell line with proper machinery to produce FVIII, when it is forced to express high levels of recombinant FVIII, it generates a cellular stress and increases the production of PAHX and BIP that retains part of the FVIII production.

\section{Material and methods}

\section{Construction of recombinant retroviral vector}

Initially, the DNA fragments of $2.29 \mathrm{~kb}$ and $2.09 \mathrm{~kb}$ referring to the heavy and the light chain of human coagulation FVIII were obtained by polymerase chain reaction (PCR) using the forward 5'- CCG CTC GAG ACC ATG
CAA ATA GAG CTC TCC ACC - 3' and 5'-AGC TTT GTT TAA ACT GAA TTC TGG GAG AAG CTT C-3' and reverse primers 5'- AGC TTT GTT TAA AC CAA AAC CCA CCA GTC TTG AAA CG -3' and 5'- ATA AGA ATG CGG CCG CTC AGT AGA GGT CCT GTG CC -3 ' respectively. As a positive control, plasmid pSP64 - VIII (American Type Culture CollectionATCC) was used containing full cDNA the FVIII.

Each amplified DNA fragment was further cloned into pCR 2.1-TOPO vector - (Invitrogen, Carisbad, CA, USA) generating HC_PCR $2.1^{+}$(vector containing FVIII heavy chain) and LC_PCR $2.1^{+}$(vector containing FVIII light chain). The light chain presents into LC_PCR 2.1 was isolated by restriction endonucleases using the sites NotI and PmeI to clone into the vector that contains heavy chain (LC_PCR $2.1^{+}$) previously cut with the same endonucleases. We confirmed sequences of the FVIII light and heavy chain as well as the junction region (53 aas N-terminal of B domain and 12 aas C-terminal B domain) in $\mathrm{rFVIII} / \mathrm{HC}+\mathrm{LC}-\mathrm{PCR} 2.1^{+}$construct by DNA sequencing (ABI Prism ${ }^{\mathrm{TM}}$ DNA Sequencer, Applied Biosystems, CA, USA). The fragments related to FVIII light and heavy chains with partially deleted B-domain were isolated using restriction $\mathrm{NotI}$ and $\mathrm{XhoI}$ endonuclease sites for cloning into pBMN-I-GFP vector previously digested with same enzymes creating BMN-FVIII $\Delta \mathrm{B}$-IGFP. The pBMN-I-GFP vector, which expresses GFP and contains IRES (internal ribosome entry site), was kindly provided by Dr. Garry P. Nolan (NIH, EUA). This construction formed NCBI NM_000132 alignment, which indicated that the constructions were in frame. The retroviral BMN-FVIII $\triangle \mathrm{B}-\mathrm{I}-\mathrm{GFP}$ vector, that expresses the partially deleted B-domain FVIII, was used to generate recombinant cell lines.

\section{PCR}

PCR was performed with specific primers for the FVIII heavy and light chains ( 5'- CTT GGA CAG TTT CTA CTG - 3', 5'- GAC GGA CAT CAG TGA TTC -3', 5'- GGT CTT CTT TGG CAA TG - 3', 5'- GGT GTG AAG GAG TCT TG -3'). Reactions were performed in $25 \mu \mathrm{l}$ of reaction volume containing $100 \mathrm{ng}$ of DNA, 1.0 U of Taq DNA polymerase (Invitrogen, Carisbad, CA, USA ), $50 \mathrm{mM} \mathrm{KCl}$, $20 \mathrm{mM}$ Tris- $\mathrm{HCl}, \mathrm{pH}$ 8.3, $1.5 \mathrm{mM} \mathrm{MgCl}_{2}, 0,2 \mathrm{mM}$ each deoxynucleotide triphosphate (dNTP), and 0.3 pmol of each specific primer. Thermocycling was performed in the GeneAmp PCR system 9700 (Perkin-Elmer/Cetus, Norwalk, $C T)$. PCR cycling conditions consisted of an initial cycle of 2 minutes at $94^{\circ} \mathrm{C}$, followed by 35 cycles of 40 seconds at $94^{\circ} \mathrm{C}, 1$ minute at $56 \mathrm{C}, 2.3$ minutes at $72^{\circ} \mathrm{C}$, and a final extension at $72^{\circ} \mathrm{C}$ for 10 minutes. The amplified products were analyzed by $1 \%$ agarose gel electrophoresis followed by ethidium bromide staining. 


\section{DNA sequencing}

DNA sequencing was performed using ABI Prism $^{\circ}$ Big $D y e^{\text {Tw }}$ Terminator Cycle Sequencing Ready Reaction Kit (Applied Biosystems, Foster City, CA, USA), according to the manufacturer's instructions, and electrophoresed, directly with an automated apparatus ABI Prism 377 DNA Sequencer (Applied Biosystems, Foster City, CA, $U S A)$. The electropherograms were analyzed by Sequence Analyzer software ABI Analysis Data Collection version 3.3 (Applied Biosystems, Foster City, CA, USA). The obtained sequences were aligned with the reference sequence available on GenBanK (NM_000132) by Sequencher software version 4.05 (Gene Codes Corp, Ann Arbor, MI, EUA).

\section{Cell culture}

PG13/LN c8 cell line and human embryonic kidney 293 cells (Hek-293) (American Type Culture Collection ATCC Manassas, VA) were maintained in Dulbecco's modified Eagle's medium (Gibco-BRL) supplemented with $2 \mathrm{mM}$ L-glutamine (Gibco-BRL, Gaithersburg, $M D$, USA), $3.7 \mathrm{~g} / \mathrm{l}$ sodium bicarbonate, $2.4 \mathrm{~g} / \mathrm{l}$ buffer HEPES, $10 \%$ fetal calf serum (HyClone, Logan, UT, USA), and $100 \mathrm{U}$ penicillin/streptomycin (Sigma, Grand Island, NY, USA). All the cell lines were maintained in a humidified incubator under $5 \% \mathrm{CO}_{2}$ at $37^{\circ} \mathrm{C}$.

\section{Transfection and transduction of cells}

The packaging PG13/LN c8 cell line was cultured into $100 \mathrm{~mm}$ plates and incubated overnight until $80 \%$ confluence. The cells were further transfected with the BMN-FVIII $\triangle \mathrm{B}-\mathrm{I}$-GFP vector using LipofectAMINE ${ }^{\mathrm{m}} \mathrm{Re}-$ agent kit (Invitrogen, Carisbad, CA, USA), following manufacturer's instructions. Four hours after transfection, cells were washed with buffer PBS (1X), reduced volume of fresh culture medium was added and the cells were incubated under $5 \% \mathrm{CO}_{2}$ in a humidified incubator. The viral supernatant was collected at 24,48 or 72 hours and used for transduction.

To infect Hek 293 cells, the supernatant with infectious virus, produced by packaging PG13/LN c8 cells after transfection, was daily collected, filtered by $45 \mu \mathrm{m}$ filter (Millipore, Billerica, MA, USA), mixed with $5.5 \mu \mathrm{g} /$ $\mu \mathrm{l}$ of polybrene (hexadimethrine bromide - Sigma, $M A$, USA) and incubated with Hek-293 cells for 16 hours. This procedure was repeated three times.

\section{Analysis and sorting of cells by fluorescent flow cytometry}

After transduction, Hek-293/BMN-FVIII BB-I-GFP cells were harvested, washed in 1X PBS, centrifuged at $335 \mathrm{~g}$, resuspended in buffer $1 \mathrm{X}$ PBS and analyzed by flow cytometry (FACsort, BD, San Jose, CA, USA) to quantify the percentage of GFP-positive cells. GFP-positive cells were sorted using a FACS Vantage (Becton Dickinson, San Jose, CA, USA).

\section{Real-time PCR}

RNA was extracted from $5 \times 10^{6}$ cells using Trizol (Invitrogen, Carisbad, CA, USA) and cDNA was synthesized using High Capacity cDNA Reverse Transcription Kit (Applied Biosystems, Foster City, CA, USA) using the following reaction: $2.0 \mu \mathrm{g}$ RNA, Random Primers 1X, RT Buffer 1X, $10 \mathrm{mM}$ dNTP's, $0.3 \mu \mathrm{l}$ RNAse OUT and 50U MultiScribe ${ }^{\text {тu }}$ MuLV reverse transcriptase in a total volume of $20 \mu \mathrm{l}$ and incubated at $25^{\circ} \mathrm{C}$ for $10 \mathrm{~min}$, $37^{\circ} \mathrm{C}$ for $120 \mathrm{~min}$. SYBR Green real-time PCR was carried out using ABI Prism 7500 Sequence Detection System (Applied Biosystems, Boston, MA) in a total volume of $15 \mu \mathrm{l}$ containing $2.5 \mathrm{pM}$ each specific primers (Table 1), SYBR Green PCR Master Mix, and $2 \mu \mathrm{l}$ of cDNA. After initial incubations at $50^{\circ} \mathrm{C}$ for $2 \mathrm{~min}$ and $95{ }^{\circ} \mathrm{C}$ for $10 \mathrm{~min}, 40$ cycles of amplification were carried out for $15 \mathrm{~s}$ at $95^{\circ} \mathrm{C}$ followed by $1 \mathrm{~min}$ at $60^{\circ} \mathrm{C}$. Human glyceraldehyde-3-phosphate dehydrogenase (GAPDH) was used as endogenous control to standardize the amount of applied RNA and to confirm the quality of the isolated RNA. Single-product amplification was confirmed by postmelting curve. Duplicate samples were measured and averaged. Relative FVIII light and heavy chain, BIP chaperone, and phytanoyl-CoA $\alpha$-hydroxylase (PAHX) transcription levels were measured as expression relative unit. The difference in CT values between the analyzed genes and endogenous control reactions $(\mathrm{dCT})$ was converted into expression relative units by setting GAPDH equal to 10000 and dividing by $2 \mathrm{dCT}$ (Albesiano et al. 2003).

\section{Activated partial thromboplastin time (APTT)}

In vitro recombinant human FVIII activity from supernatants of transduced Hek 293 cells cultured in the presence of inducers of calcium ionophore (A-23187) protein secretion $(3 \mu \mathrm{g} / \mathrm{ml})$, and Phorbol 12-myriastate

Table 1 Primers used in PCR Real-time analysis

\begin{tabular}{ll}
\hline Primer Name & Primer sequence \\
\hline P5 BiPH & 5'- CCA ACG CCA AGC AAC CAA AG-3' \\
P3 BiPH & 5'- CTT CTC CCC CTC CCT CTT AT-3' \\
P5 FytCoAH & 5'- CTG TCT GGT TGT GCT CCC A-3' \\
P3 FytCoAH & 5'- GCC TTG TIT TCC TCG TAG TCC-3' \\
P5 CHFVIII & 5'- CAC TCT TGA TGG ACC TTG GAC-3' \\
P3 CHFVIII & 5'- TCG TAG TTG GGG TTC CTC TG-3' \\
P5 CLFVIII & 5'- GAT GGG AAG AAG TGG CAG AC-3' \\
P3 CLFVIII & 5'- GTG CAA ACG GAT GTA TCG AGC-3' \\
P5 GAPDH & 5'- GCC TCA AGA TCA TCA GCA ATG C-3' \\
P3 GAPDH & 5'- CAT GGA CTG TGG TCA TGA GTC CT-3' \\
\hline
\end{tabular}


13-acetate (PMA) $(6 \mu \mathrm{g} / \mathrm{ml})$ for 24 hours were quantified by measuring the FVIII-dependent generation of thrombin using one stage clotting assay ATTP (Biomérieux, Sweden). FVIII deficient plasma was used as substrate, human plasma purified FVIII Verify - Reference plasma - (Organon Teknika, Durham) was used as a positive qualitative standard, and $1,000 \mathrm{mU}$ was defined as $200 \mathrm{ng}$ FVIII/ml or $1 \mathrm{U}$ as $100 \%$ of activity. For the thrombin activation assay, conditioned medium of transduced Hek 293 cells was diluted (1:5) and incubated at room temperature. After incubation, the FVIII activity was measured by COAG-A-MATE ${ }^{\ominus} X M$ - Organon Teknika according to the manufacturer's specifications.

\section{Statistical analysis}

The normality of the data was examined by Shapiro-wilk test using $\mathrm{R}$ (version 3.0) $\mathrm{p} \leq 0.05$. Then, the data was analyzed applying t-test with Mann-Whitney test or nonparametric correlation (Spearman) test, one-tail using the GraphPad InStat software, version 3.0 for Windows (GraphPad Software, San Diego, CA, USA; http://tools.invitrogen.com/content/sfs/manuals/ FreeStyle_293_F_Cells_man.pdf), with the level of significance set at $\mathrm{p} \leq 0.05$.

\section{Results}

\section{Construction of the BMN-FVIII $\triangle \mathrm{B}-\mathrm{I}-\mathrm{GFP}$ retroviral plasmid}

To generate the retrovirus bicistronic vector $B M N$ FVIII $\triangle B-I-G F P$, rFVIII $\triangle B$ was amplified by PCR using specific primers to amplify the heavy chain (domain A1, A2 plus 53 aas $\mathrm{N}$-terminal of $\mathrm{B}$ domain) and the light chain (domains A3, C1, C2 plus 12 aas C-terminal B domain) of hFVIII. These DNA fragments were joined and generated one common fragment with $4.3 \mathrm{~kb}$ DNA. This DNA fragment was first cloned into pCR2.1-TOPO vector (Figure 1: lanes 1,2$)$ and then into expression vector pBMN-I-GFP (Figure 1: lanes 3,4). The cloned sequence authenticity was confirmed by DNA sequencing.

After the retroviral transduction, Hek-293/BMNFVIII $\triangle B$-I-GFP cells were sorted by FACS to obtain a cell population with high level of eGFP. Fifteen days later, the flow cytometry analysis showed that all derived population (Hek-293/BMN-FVIIIAB-I-GFP 1-15) were GFP positive and presented the proportion of $\mathrm{GFP}^{+}$cells higher than $40 \%$ (Table 2).

\section{Correlation between percentage of $\mathrm{GFP}^{+}$cells and FVIII mRNA expression level}

We evaluated the expression of the light and heavy chain of FVIII by semi-quantitative reverse transcription-PCR in fifteen isolated cell population and compared with the percentage of GFP positive cells to assess the GFP efficiency as a gene marker to select rFVIII cell producers. The GAPDH gene was used as endogenous control, showing a

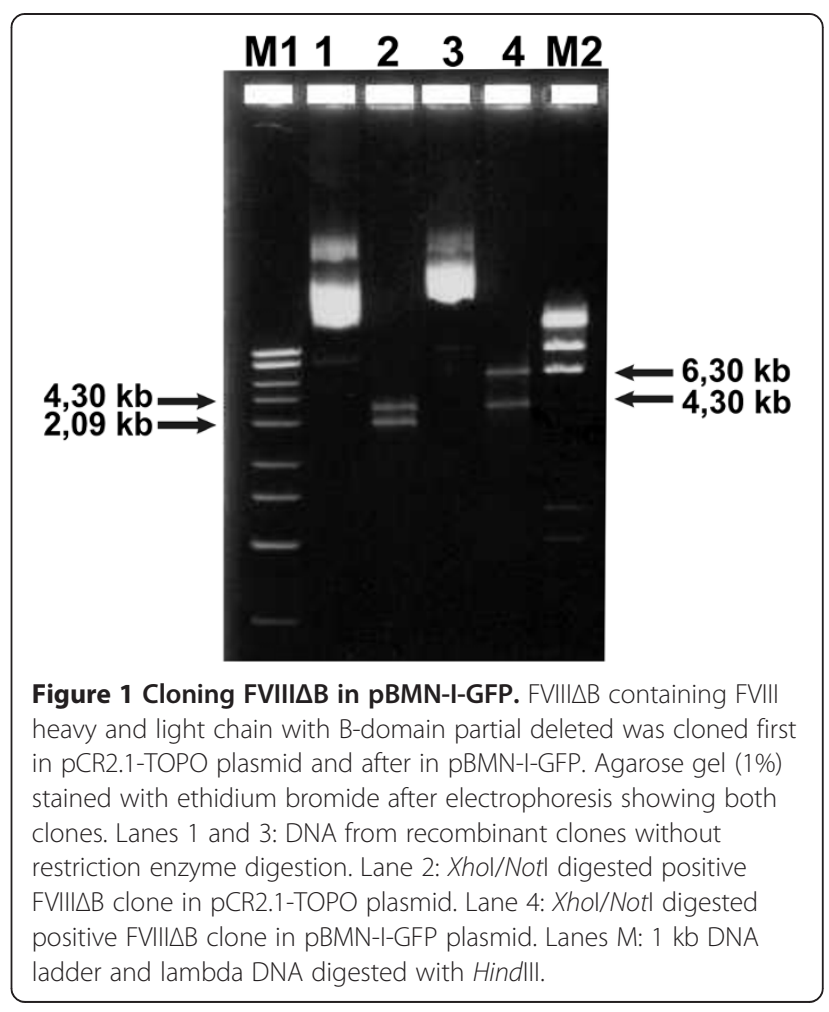

Table 2 Biological activity of FVIII secreted by Hek-293/ BMN-FVIIIDB-I-GFP

\begin{tabular}{|c|c|c|c|}
\hline Sample & $\%$ of GFP expression & Activity (\%) & $\mathrm{IU} / \mathrm{mL}$ \\
\hline Culture medium DMEN & - & 1.5 & - \\
\hline S. Cell pop. 01 & 74.0 & 14.0 & 0.1 \\
\hline S. Cell pop. 02 & 80.0 & 11.1 & 0.1 \\
\hline S. Cell pop. 03 & 76.5 & 10.0 & 0.1 \\
\hline S. Cell pop. 04 & 72.1 & 34.6 & 0.3 \\
\hline S. Cell pop. 05 & 70.0 & 41.9 & 0.4 \\
\hline S. Cell pop. 06 & 70.5 & 21.7 & 0.2 \\
\hline S. Cell pop. 07 & 68.1 & 1.9 & 0.0 \\
\hline S. Cell pop. 08 & 63.8 & 2.2 & 0.0 \\
\hline S. Cell pop. 09 & 44.3 & 2.9 & 0.0 \\
\hline S. Cell pop. 10 & 43.4 & 20.1 & 0.2 \\
\hline S. Cell pop. 11 & 44.9 & 4.1 & 0.0 \\
\hline S. Cell pop. 12 & 48.2 & 75.8 & 0.7 \\
\hline S. Cell pop. 13 & 53.6 & 18.5 & 0.1 \\
\hline S. Cell pop. 14 & 62.5 & 47.9 & 0.4 \\
\hline S. Cell pop. 15 & 48.6 & 37.1 & 0.3 \\
\hline
\end{tabular}

Analysis of biological activity of FVIII secreted by Hek-293/BMN-FVIIIDB-I-GFP using TTPA assay. S Supernatant, Cell pop Cell population, Hek-293 human embryonic kidney epithelial cells. 


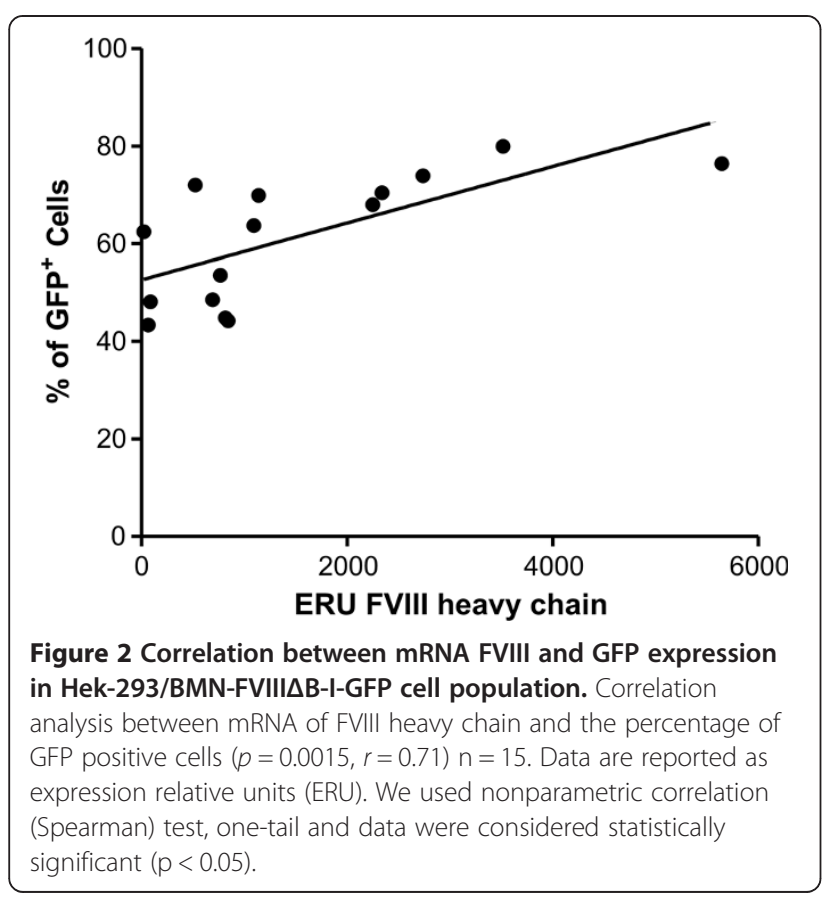

homogeneous profile expression among the studied samples $(\mathrm{SD}=0,8)$. As expected, we found a positive correlation between the mRNA expression of FVIII and the percentage of $\mathrm{GFP}^{+}$cells selected in all Hek-293/BMN-FVIII $\Delta B-I-G F P$ clones $(r=0.71, p=0.0015)$ (Figure 2).

mRNA expression of BIP and PAHX in the Hek-293/BMNFVIIIAB-I-GFP cell population

Considering that rFVIII expression in cell lines can be modulated by proteins that interact with the FVIII molecule and limit mRNA translation, transportation into the Golgi complex and secretion, we evaluated the mRNA expression level of two proteins that are known for interacting with FVIII (BIP and PAHX). The real-time PCR analysis of the 15 selected population showed an increase of $3.1 \pm 1.4$ fold of BIP mRNA expression on Hek-293/BMN-FVIII $\Delta B$ -
I-GFP cell population when compared to non-transfected Hek-293 cells $(p=0.0054)$ (Figure 3A). We also observed an induction of $97.8 \pm 0.5$ fold expression of mRNA PAHX in the cell population producers of rFVIII $(p=0.0016)$ (Figure $3 \mathrm{~B}$ ). These results indicate that the overexpression of FVIII mRNA induces BIP and PAHX expression because of the cellular stress created by the recombinant protein.

\section{Protein secretion of FVIII and the mRNA expression of BIP and PAHX}

To investigate the impact of the expression FVIII-ligand proteins in the rFVIII secretion, we verified the correlation between expression (BIP and PAHX) and biological activity of the FVIII.

Among the FVIII selected population, we observe an inversely proportional correlation between mRNA BIP expression and the value of the biological activity $(p=0.009 r=-0.60)$ (Figure 4A). Similar results were obtained when we compared FVIII secretion to the expression levels of mRNA of PAHX, showing a negative correlation $(p=0.042 r=-0.46)$ (Figure 4B).

\section{Discussion}

In this work, we used retroviral system for the expression of FVIII recombinant molecule that contains light and heavy chains of the protein and a small segment of the B domain. Native full-length human FVIII consists of 2332 amino acid residues divided into the following domains: A1-a1-A2-a2-B-a3-A3-C1-C2; the heavy chain comprises the domains $\mathrm{A} 1-\mathrm{a} 1-\mathrm{A} 2-\mathrm{a} 2-\mathrm{B}$ and light chain a3-A3-C1-C2. The chains as linked by a divalent metal ion (Shen et al. 2008; Lenting et al. 2010). Previous reports in the literature showed that B domain does not play an important role in the biological activity protein and can be removed without losing its function for blood coagulation (Toole et al. 1986). rFVIII constructs with partial deleted B domain have shown the presence of biologically active FVIII in the supernatant of different cell cultures (Meulien et al. 1988; Lind et al. 1995;
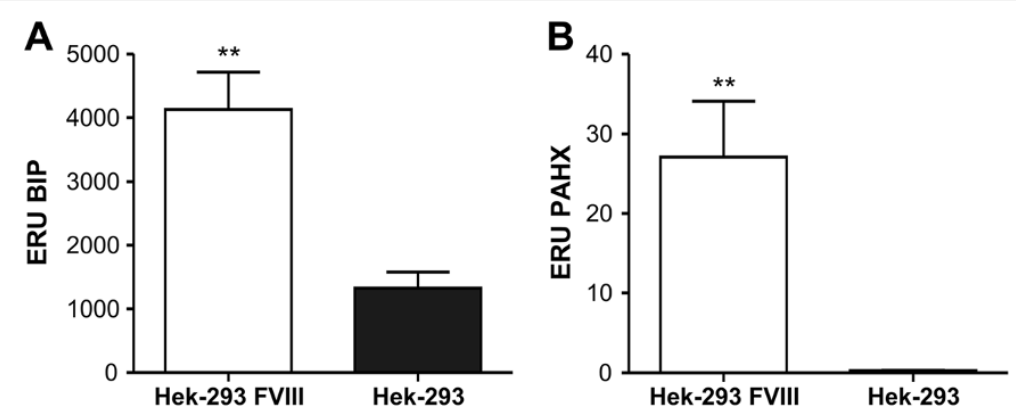

Figure 3 Gene expression of mRNA of BIP and PAHX among Hek-293/BMN-FVIIIAB-I-GFP cell population. A and B) Gene expression of mRNA of BIP and PAHX in Hek-293/BMN-FVIIIAB-I-GFP cells and Hek-293 non-transfected cells. Data are reported as expression relative units (ERU) and are represented as the means \pm SEM. We used nonparametric t-test (Mann Whitney), one-tail and data were considered statistically significant $(p<0.05)$. The asterisks denote significant differences compared to non-transfected Hek-293 (** $p<0.01)$. 

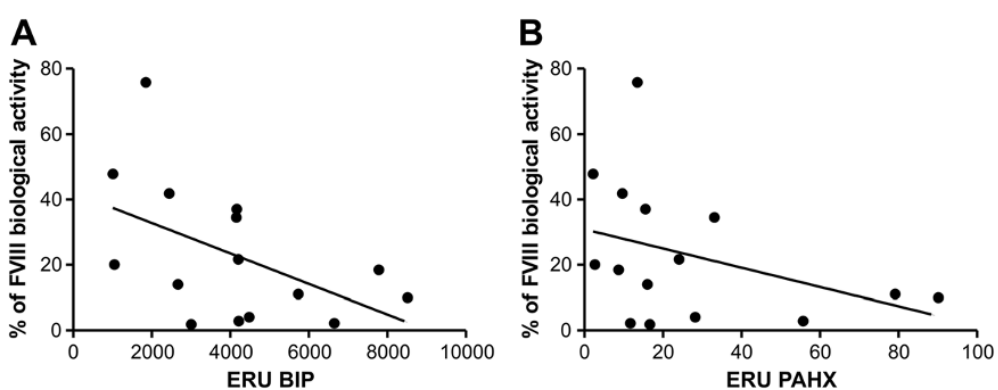

Figure 4 Comparison between transcription levels BIP and PAHX and FVIII secretion. A) Correlation analysis between mRNA of BIP and the percentage of FVIII biological activity ( $p=0.0090, r=-0.60)$. B) Correlation analysis between mRNA of PAHX and the percentage of FVIII biological activity $(p=0.042, r=-0.46)$. Data are reported as expression relative units (ERU). We used nonparametric correlation (Spearman) test, one-tail and data were considered statistically significant $(p<0.05)$.

Herlitschka et al. 1998; Burton et al. 1999). Another advantage is the removal of the B-domain is that it allows nano-filtration of the recombinant protein enhancing purity and safety. The B-domain is highly glycosylated, but it is not essential for the pro-coagulant function of the protein. The B domain may be important for intracellular processing and trafficking during biosynthesis (Pipe 2009). The recombinant products in the market are produced in murine cell lines that have in their structure the antigenic carbohydrate epitopes $\alpha$-Gal and Neu5Gc, which are absent in human-FVIII. The FVIII production in a human cell line avoids the potential incorporation of non-human glycan epitopes (Kannicht et al. 2013).

Human cell lines for the production of FVIII are highlighted as an improvement in the treatment of Hemophilia A. These cells have proper machinery for PTM and secretion of FVIII. In this work, we evaluated if the forced expression of FVIII in a human cell line (Hek 293) can alter the expression of FVIII-ligand proteins (BIP e PAHX) what can influence FVIII production. Our work showed that the transcription levels of mRNA of BIP and PAHX in the Hek-293/BMNFVIIISB-I-GFP were increased in relation to the nontransfected cell. Similar results have been described by (Becker et al. 2004) who demonstrated that FVIII mRNA expression induce a rather moderate increase of BIP transcription in COS cells transfected with rFVIII full length and B-domain deleted, reflecting the cellular stress created by the recombinant protein.

The mRNA expression levels of BIP and PAHX were reversely proportional to the secretion level of biologically active FVIII. BIP protein is supposed to interact with A1 domain of FVIII and decrease FVIII secretion (Marquette et al. 1995; Dorner et al. 1992; Dorner and Kaufman 1994). To solve this problem, other authors (Miao et al. 2004; Srour et al. 2008) suggest the construction of rFVIII molecules with mutations within the A1 domain to reduce the interaction with BIP chaperone protein (Miao et al. 2004), or the addition of a glycosylation site in the $\mathrm{N}$ terminal region of FVIII protein (Srour et al. 2008).

PAHX mRNA has been found in specific tissues like liver and kidney. As Hek-293 is a kidney derived cell line, we evaluated if PAHX expression could alter FVIII secretion. Our work shows that Hek 293 cell population with the highest FVIII secretion levels presented low expression of mRNA PAHX. Chen et al. showed that PAHX overexpression in BHK cells producing $\mathrm{rFVIII}$ is related to $70 \%$ decrease of FVIII protein expression, according to quantification of bands on the immunoblotting (Chen et al. 2001).

Many strategies have already been applied as an attempt to improve FVIII secretion and to diminish the costs of rFVIII production. The production of recombinant FVIII in murine cells should be replaced by the production in human cells. However, it is necessary to evaluate the stress caused by the high expression of exogenous FVIII in human cells and develop strategies for inhibiting and/or silencing proteins as BIP and PAHX. Our work suggests the screening of BIP and PAHX mRNA of FVIII Hek 293cell producers as a new perspective to improve and facilitate FVIII production.

\section{Competing interest}

The authors declare that they have no competing interest.

\section{Authors' contributions}

RES was responsible for experimental design, cell cultures and statistics analyses, P-C revising it critically for important intellectual content, EMR was responsible for cell cultures and acquisition of data, deALAM conducted cloning experiments, PPVB was responsible for flow cytometry analyzes, KS, FAM, and CDT were responsible for the overall experimental design and coordination of the project. All authors read and approved the final manuscript.

\section{Acknowledgments}

This study was supported by the Center for Cell-based Therapy (CTC) and Fundação de Amparo à Pesquisa do Estado de São Paulo - FAPESP. The authors acknowledge Dr. Garry P. Nolan for contributing with the pBMN-I -GFP vector and David Marco Antonio for statistical support. We thank Fernanda Udinal and Alessandra Almeida for English language support. We also thank Sandra Navarro Bresciani for preparing the figures. 


\section{Author details}

${ }^{1}$ Hemotherapy Center of Ribeirão Preto , Faculty of Medicine in Ribeirão Preto-FMRP, University of São Paulo-USP, São Paulo, Brazil. ²Faculty of Medicine in Ribeirão Preto-FMRP, University of São Paulo-USP, São Paulo, Brazil. ${ }^{3}$ Faculty of Pharmaceutical Sciences in Ribeirão Preto-FCFRP, University of São Paulo-USP, São Paulo, Brazil. ${ }^{4}$ Hemocentro de Ribeirão Preto, National Institute of Science and Technology in Stem Cell and Cell Therapy, Avenida Tenente Catão Roxo, 2501 - Ribeirão Preto, São Paulo 14051-140, Brazil.

Received: 27 June 2013 Accepted: 28 June 2013

Published: 18 July 2013

\section{References}

Albesiano E, Messmer BT, Damle RN, Allen SL, Rai KR, Chiorazzi N (2003) Activation-induced cytidine deaminase in chronic lymphocytic leukemia B cells: expression as multiple forms in a dynamic, variably sized fraction of the clone. Blood 102:3333-3339

Antunes SV, Vicari P, Cavalheiro S, Bordin JO (2003) Intracranial haemorrhage among a population of haemophilic patients in Brazil. Haemophilia 9(5):573-577

Baxter (2010) Advate ${ }^{\oplus}$ Prescribing Information. Baxter, Deerfield

Becker S, Simpson JC, Pepperkok R, Heinz S, Herder C, Grez M, Seifried E, Tonn T (2004) Confocal microscopy analysis of native full length and B-domain deleted coagulation factor VIII trafficking in mammalian cells. Thromb Haemost 1:23-35

Brown HC, Gangadharan B, Doering CB (2011) Enhanced biosynthesis of coagulation factor VIII through diminished engagement of the unfolded protein response. J Biol Chem 286(27):24451-7

Burton M, Nakai H, Colosi P, Cunningham J, Mitchell R, Couto L (1999) Coexpression of factor VIII heavy and light chain adeno-associated viral vectors produces biologically active protein. Proc Natl Acad Sci USA 96 (22):12725-12730

Chen C, Wang Q, Fang X, Xu Q, Chi C, Gu J (2001) Roles of Phytanoyl-CoA Hydroxylase in Mediating the Expression of Human Coagulation Factor VIII. J Biol Chem 276(49):46340-46346

Dorner AJ, Kaufman RJ (1994) The levels of endoplasmic reticulum proteins and ATP affect folding and secretion of selective proteins. Biologicals 22(2):103-12

Dorner AJ, Wasley LC, Kaufman RJ (1992) Overexpression of GRP78 mitigates stress induction of glucose regulated proteins and blocks secretion of selective proteins in Chinese hamster ovary cells. EMBO J 11(4):1563-71

Durocher Y, Butler M (2009) Expression systems for therapeutic glycoprotein production. Curr Opin Biotechnol 20(6):700-7

Durocher Y, Perret S, Kamen A (2002) High-level and high-throughput recombinant protein production by transient transfection of suspensiongrowing human 293-EBNA1 cells. Nucleic Acids Res 15:30-32

Ghosh K (2004) Management of haemophilia and its complications in developing countries. Clin Lab Haematol 26(4):243-251

HealthCare B (2009) Kogenate ${ }^{\oplus}$ Prescribing Information. Bayer HealthCare, Leverkusen

Herlitschka SE, Schlokat U, Falkner FG, Dorner F (1998) High expression of a Bdomain deleted factor VIII gene in a human hepatic cell line. J Biotechnol 61 (3):165-173

Invitrogen Corporation (2007) User Manual Free Style TM 293-F Cells (R790-07)., http://www.graphpad.com/support/instat-3-updates/

Jiang R, Monroe T, McRogers R, Larson PJ (2002) Manufacturing challenges in the commercial production of recombinant coagulation factor VIII. Haemophilia $8(2): 1-5$

Kannicht C, Ramström M, Kohla G, Tiemeyer M, Casademunt E, Walter O, Sandberg H (2013) Characterisation of the post-translational modifications of a novel, human cell line-derived recombinant human factor VIII. Thromb Res 131(1):78-88

Lee C (1999) Recombinant clotting factors in the treatment of hemophilia. Thromb Haemost 2:516-524, Review

Lenting PJ, Christophe OD, Guéguen P (2010) The disappearing act of factor VIII. Haemophilia 16(102):6-15

Lind P, Larsson K, Spira J, Sydow-Bäckman M, Almstedt A, Gray E, Sandberg H (1995) Novel forms of B-domain-deleted recombinant factor VIII molecules. Construction and biochemical characterization. Eur J Biochem 232(1):19-27
Marquette KA, Pittman DD, Kaufman RJ (1995) A 110-amino acid region within the A1-domain of coagulation factor VIII inhibits secretion from mammalian cells. J Biol Chem 270(17):10297-10303

Meulien P, Faure T, Mischler F, Harrer H, Ulrich P, Bouderbala B, Dott K, Sainte Marie M, Mazurier C, Wiesel ML (1988) A new recombinant procoagulant protein derived from the cDNA encoding human factor VIII. Protein Eng 2 (4):301-306

Miao HZ, Sirachainan N, Palmer L, Kucab P, Cunningham MA, Kaufman RJ, Pipe SW (2004) Bioengineering of coagulation factor VIII for improved secretion. Blood 103(9):3412-9

Morris JA, Dorner AJ, Edwards CA, Hendershot LM, Kaufman RJ (1997) Immunoglobulin binding protein (BiP) function is required to protect cells from endoplasmic reticulum stress but is not required for the secretion of selective proteins. J Biol Chem 272(7):4327-4334

Neidhardt E, Koval R, Burke E, Warne N (2005) In vitro evaluation of B-domain deleted recombinant factor VIII (ReFacto) stability during simulated continuous infusion administration. Haemophilia 11(4):319-325

Picanço V, Heinz S, Bott D, Behrmann M, Covas DT, Seifried E, Tonn T (2007) Recombinant expression of coagulation factor VIII in hepatic and nonhepatic cell lines stably transduced with third generation lentiviral vectors comprising the minimal factor VIII promoter. Cytotherapy 9(Suppl 8):785-94

Pipe SW (2009) Functional roles of the factor VIII B domain. Haemophilia 15(6):1187-96

Shen BW, Spiegel PC, Chang CH, Huh JW, Lee JS, Kim J, Kim YH, Stoddard BL (2008) The tertiary structure and domain organization of coagulation factor VIII. Blood 111(3):1240-1247

Srour MA, Grupp J, Aburubaiha Z, Albert T, Brondke H, Oldenburg J, Schwaab R (2008) Modified expression of coagulation factor VIII by addition of a glycosylation site at the $\mathrm{N}$ terminus of the protein. Ann Hemato 87(2):107-12

Stanley SL Jr (2006) The need for continuing vigilance addressing the threat for transmission of blood-borne infectious disease. Semin Hematol 43(2 Suppl 3):S17-22

Swiech K, Kamen A, Ansorge S, Durocher Y, Picanço-Castro V, Russo-Carbolante EM, Neto MS, Covas DT (2011) Transient transfection of serum-free suspension HEK 293 cell culture for efficient production of human rFVIII. BMC Biotechnol 11:114

Thomas P, Smart TG (2005) HEK293 cell line: a vehicle for the expression of recombinant proteins. J Pharmacol Toxicol Methods 51(3):187-200

Toole JJ, Pittman DD, Orr EC, Murtha P, Wasley LC, Kaufman RJ (1986) A large region (approximately equal to $95 \mathrm{kDa}$ ) of human factor VIII is dispensable for in vitro procoagulant activity. Proc Natl Acad Sci USA 83(16):5939-5942

Wyeth Pharma (Pfizer) (2007) ReFacto ${ }^{\oplus}$ Prescribing Information. Wyeth Pharma (Pfizer), Madison

Zago MA, Covas DT, Ismael SJ, Bottura C (1987) Splenic function in haemophilia Haematologia (Budap) 20 1:57-62

doi:10.1186/2193-1801-2-328

Cite this article as: Rodrigues et al:: Quantitative correlation between transcriptional levels of ER chaperone, peroximal protein and FVIII productivity in human Hek-293 cell line. SpringerPlus 2013 2:328.

\section{Submit your manuscript to a SpringerOpen ${ }^{\circ}$ journal and benefit from:}

- Convenient online submission

$\checkmark$ Rigorous peer review

- Immediate publication on acceptance

- Open access: articles freely available online

- High visibility within the field

- Retaining the copyright to your article

Submit your next manuscript at springeropen.com 